\begin{tabular}{c} 
International Journal of Engineering \& Technology, $7(2.21)(2018) 367-371$ \\
International Journal of Engineering \& Technology \\
WPC \\
Research paper $:$ ww. sciencepubco.com/index.php/IJET \\
\hline
\end{tabular}

\title{
Effects of zero defects approach-a case study at an Indian industry
}

\author{
K. Karunakaran ${ }^{1 *}$, R. Saravanan ${ }^{2}$, P. Venkumar ${ }^{3}$, R. Sridhar ${ }^{4}$ \\ ${ }^{1}$ Associate Professor, School of Engineering, VISTAS, Chennai, India. \\ ${ }^{2}$ Professor \& Dean, Ellenki College of Engineering and Technology, Hyderabad, India. \\ ${ }^{3}$ Professor \& Deputy Registrar, Kalasalingam Academy of Research and Education (KARE), Tamil Nadu, India. \\ ${ }^{4}$ Assistant Professor, School of Engineering, VISTAS, Chennai, India. \\ *Corresponding author E-mail:ksivasakthi1966@gmail.com
}

\begin{abstract}
Quality is free when reaches zero defects, quality is measured various aspects. The rework is carried out when the product finish not up to the standard, which added additional expenditure. On other side if there is no chance for rework the cost of raw material and value added cost up to that non conformity is lost. This work shares a success story and reveals a systematic scientific approach to reach zero defects. The case study conducted in the leading supplier who focuses on climate and energy efficient solutions. The traditional powerful quality tools employed to focus, understanding and analyse the problem. The Decision support system preferred and adopted to solve the problem with affordable cost. The outcomes of this work measured in terms of modern Total Productive Maintenance style that is in terms of Productivity, Quality, Cost, Delivery, Safety, Motivation and Morale (PQCDSM). The results in all the way found more significant.
\end{abstract}

Keywords: Powerful quality tools, decision support system, modern total productive maintenance, motivation and morale (PQCDSM).

\section{Introduction}

Zero-defect manufacturing strategy bring the enormous business prospect to firm like higher productivity, better quality, highreturn of investment and innovation etc. [1] The organizational and operational decision making are recently supported by specially designed information system called Decision support systems (DSS) which provides interface to decision maker. Boshkoska et al. [2] addressed quality ranking related issue and suggested DSS with integration of quality standards of the concern and expectation of experts. Another interesting case is deduction of faults and activation of auto recovery without human intervention that is real time quality control capability, discussed. by Ozgur and Wendel [3]. The fuzzy logic used for space application was discussed for fault deduction under uncertainty by Ribeiro [4]. [5] proposed about fuzzy logic based intelligent DSS which detects, analyses the root cause and rectifying the problem and validated with real coal mill data. [6] presented a case study to achieve zero structural defects in press shop of a sheet metal industry. [7] reviewed about condition monitoring in machining process with neural networks. Saravanan et al [8] discussed importance of measurement for improvement and achieved zero defects in drill holed products by Total Productive Maintenance approach and suggested to review the result in terms of PQCDSM. In this paper valve manufacturing unit considered. the powerful tools and renowned techniques were used and results are measured in terms of PQCDSM [9].

\section{Materials and methods}

\section{Problem background}

The organization is a leading supplier which focuses on climate and energy efficient solutions. Wide range of products includes the valves, filters and regulators. This study focuses on refrigerator valves in particularly shut-off valve -STC manufacturing (Figure 1). Specific application (Cold Room) of such valves is depicted in Figure 2.

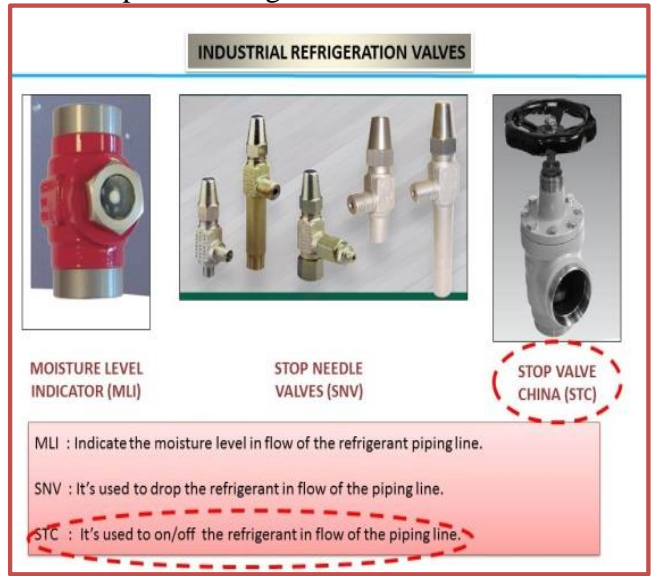

Figure 1: Product and its purpose 


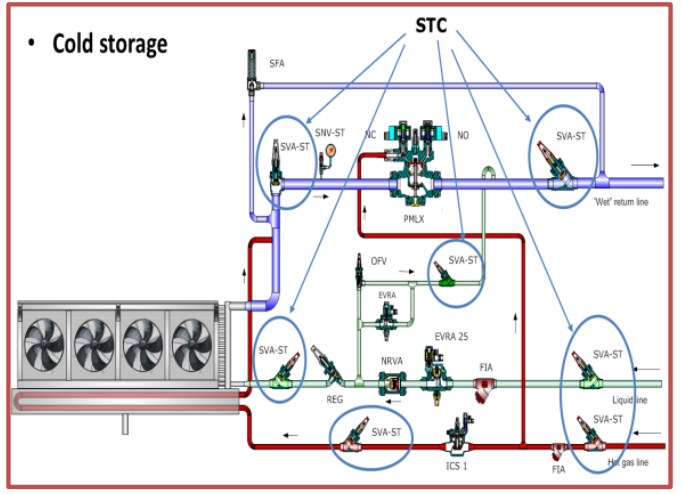

Figure 2: Sample application of the Product

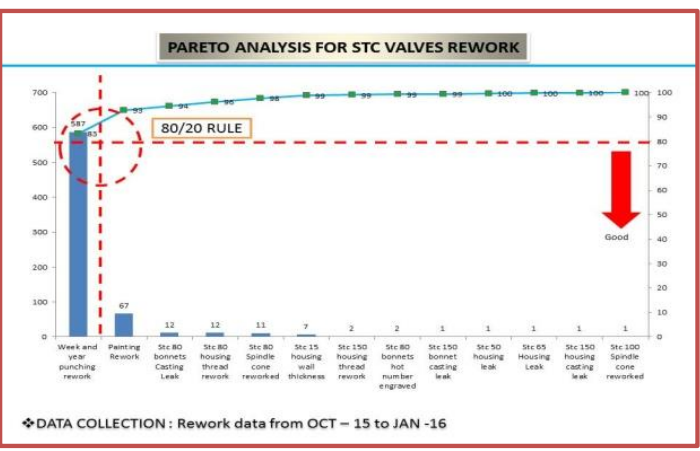

Figure 3: Pareto analysis

\section{Problem identification}

According to Six Sigma, the Rework is one of the eight major losses. Hence the Problem identification was carried out with help of rework history of STC valves and analysed by means of Pareto analysis. The self explanatory analysis has furnished in Figure 3. The week and year Punch reworks encountered many times (587). The phenomenon wise week and Year punch defects were analysed and furnished in Figure 4. Week and Year of manufacture information is mandatory for the customer claims. It usually punches on the part as week followed by year. For example, the punch mark is 0716 means seventh week of the year 2016 (Refer Figure 5). It provides traceability of finished goods that is helps to track back on their production records. It is essential easy identification for any customer complaints on the specific valve. So its quality has very high priority. The existing method is manual and it is sequentially depicted in Figure 6.

\section{Problem analysis}

The brainstorming study session was conducted and prepared Ishikawa diagram (Cause and Effect Diagram). The possible cases were encircled with green (Refer Figure 7). The root cause analyses were carried and they are diagrammatically depicted in Figure 8 to Figure 10 for the phenomenon uneven punching, punching with less visibility and missing of Punching respectively.

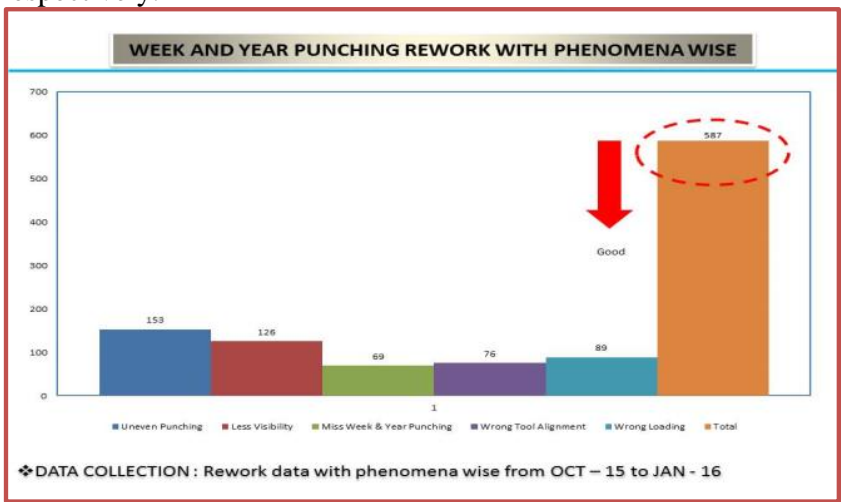

Figure 4: Contribution of different phenomenon for the defect

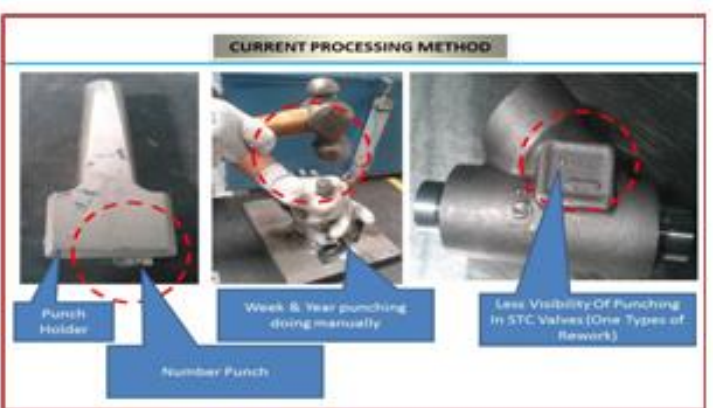

Figure 5: Punch mark of week and year of manufactured

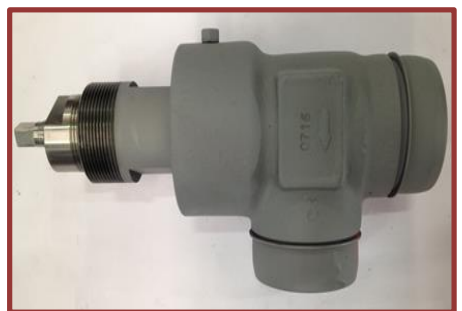

Figure 6: Traditional method \& defect

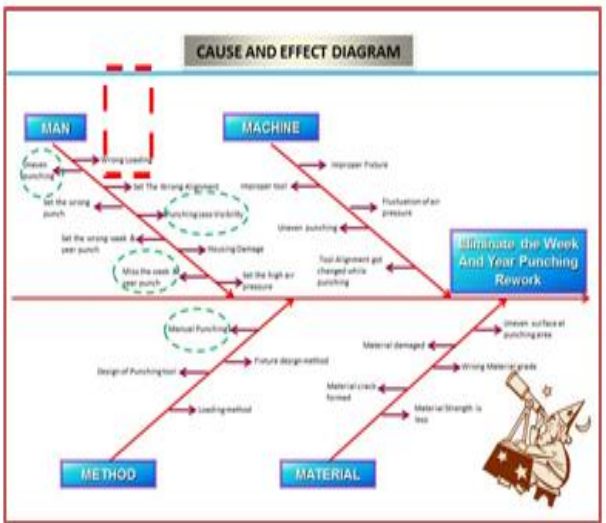

Figure 7: Results of brainstorming

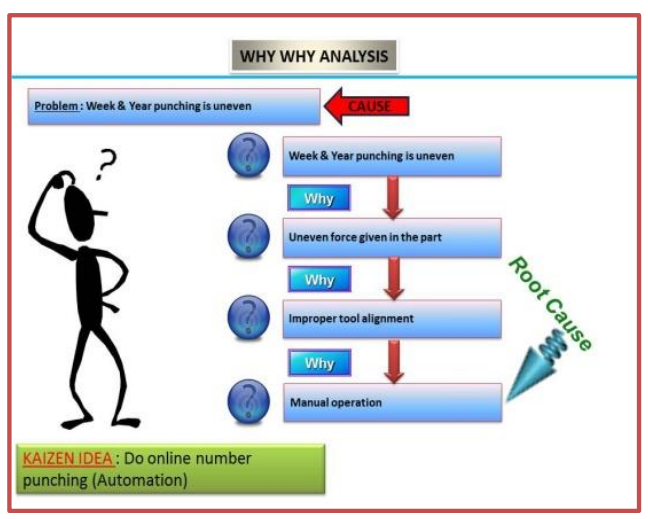

Figure 8: Root cause analysis (a) 


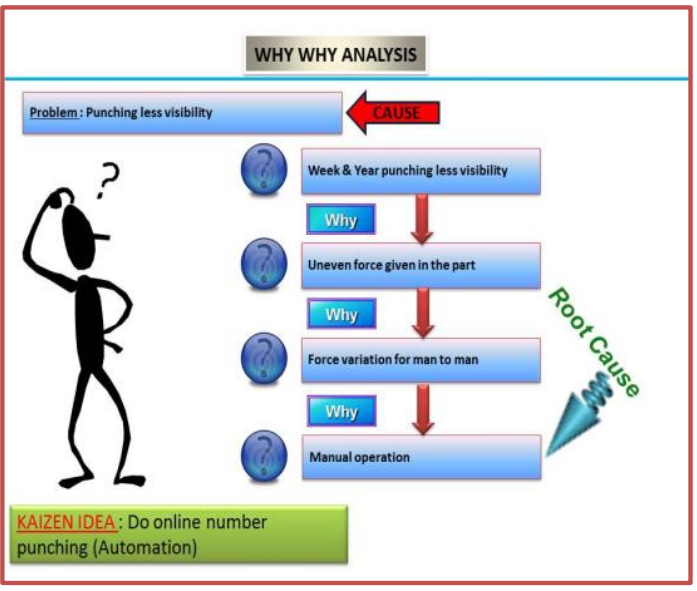

Figure 9: Root cause analysis (b)

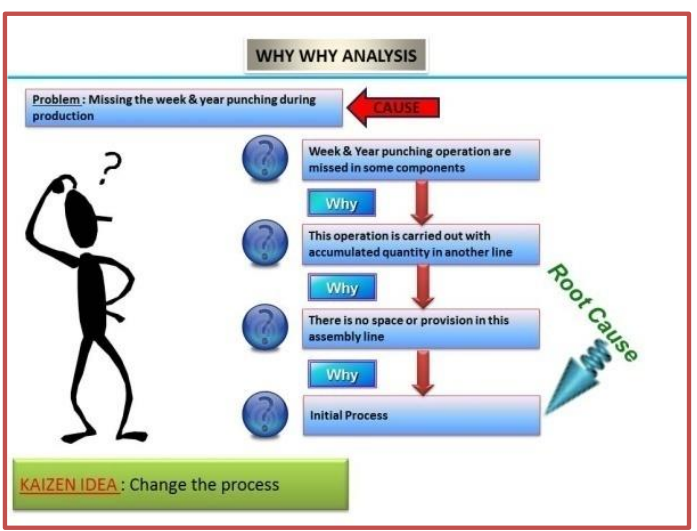

Figure 10: Root cause analysis (c)

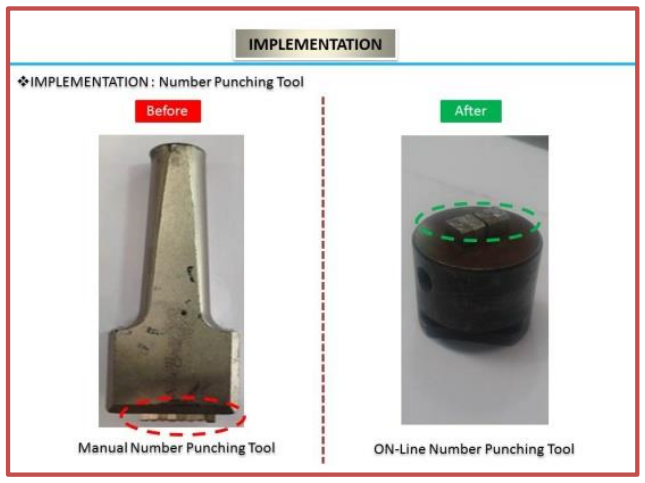

Figure 11: Tools for traditional and new method

\section{Solution to the problem}

An on-line punching system is designed and implemented. For better understanding the details are comparatively discussed with illustrative diagrams from Figure 11 to Figure 17.

\section{Results and discussions}

Saravanan et al (2001) the validation is carried out in various ways that is PQCDSM. The results of the proposed method measured and presented in Figure 18. The solution effects in Productivity, Quality, Cost, Delivery, Safety, Motivation and Morale wise measured and compared. The details are diagrammatically illustrated from Figure 19 to Figure 23.

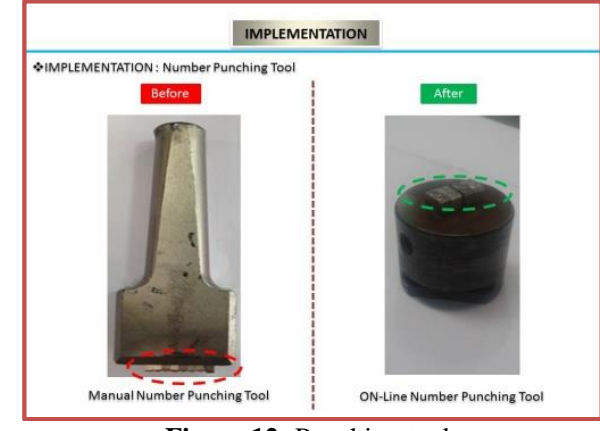

Figure 12: Punching tools

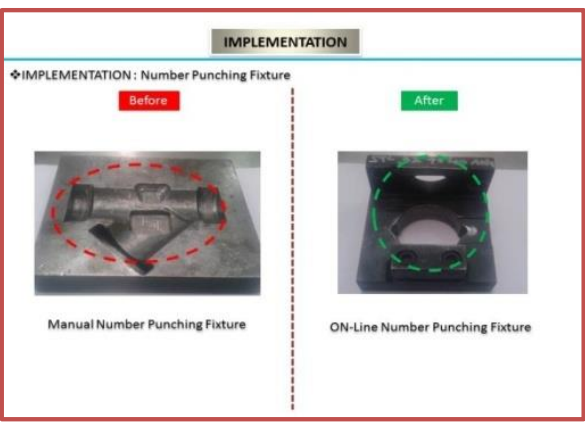

Figure 13: Punching fixtures

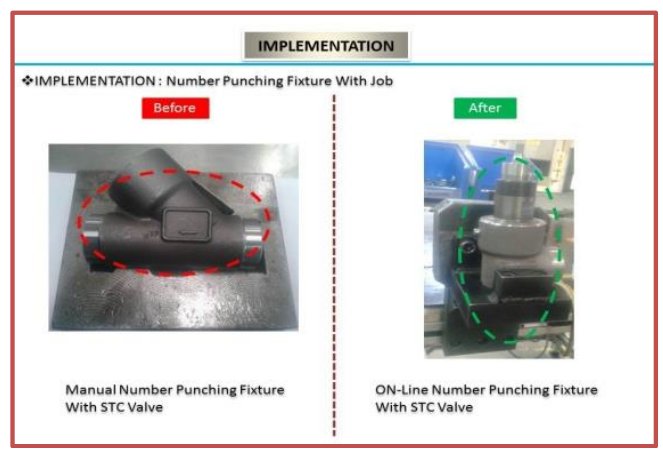

Figure 14: Punching fixture with housing

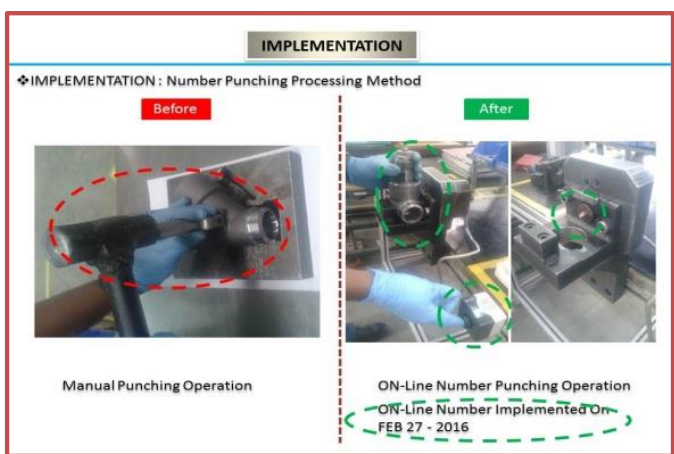

Figure 15: Punching operation methods

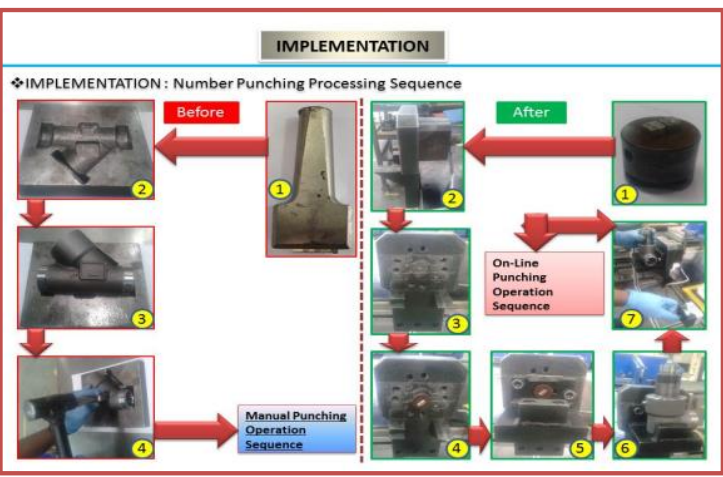

Figure 16: Punching operation sequences 


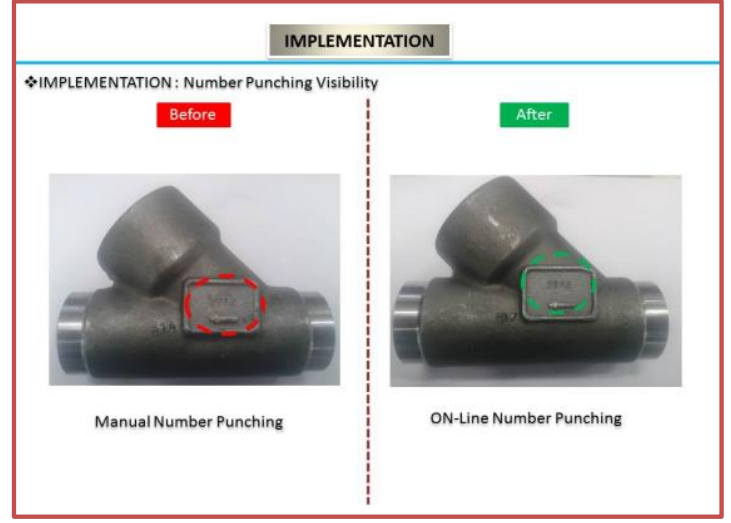

Figure 17: Punching visibilities

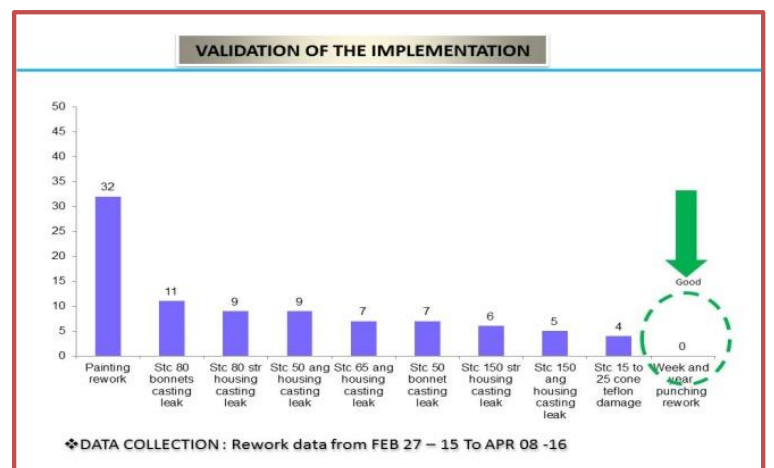

Figure 18: Zero Rework achieved in punch of week and year of manufactured and other quality defects

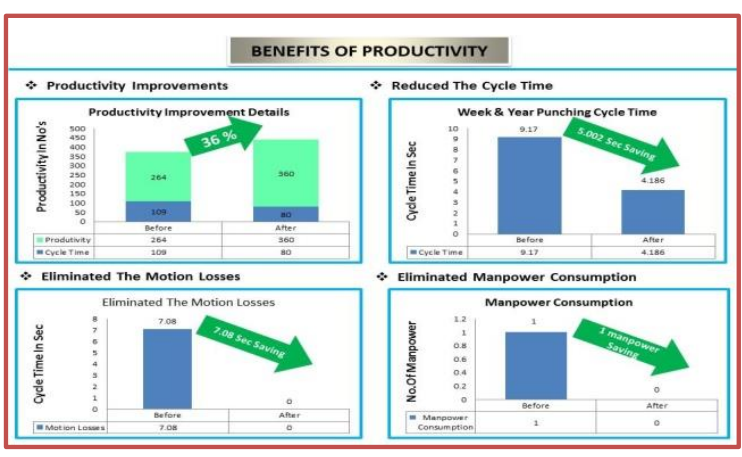

Figure 19: Productivity benefits

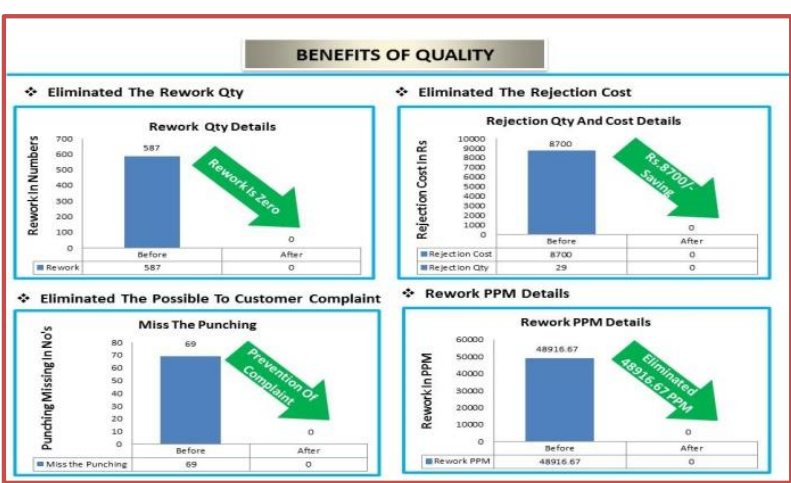

Figure 20: Benefits on quality

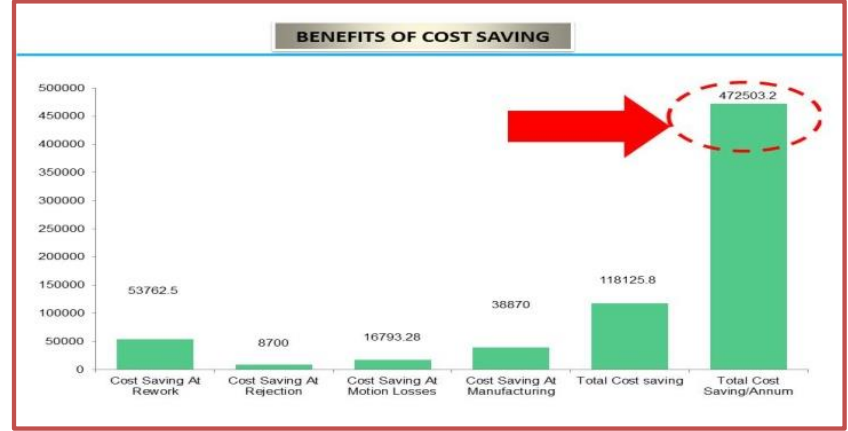

Figure 21: Benefits by cost saving

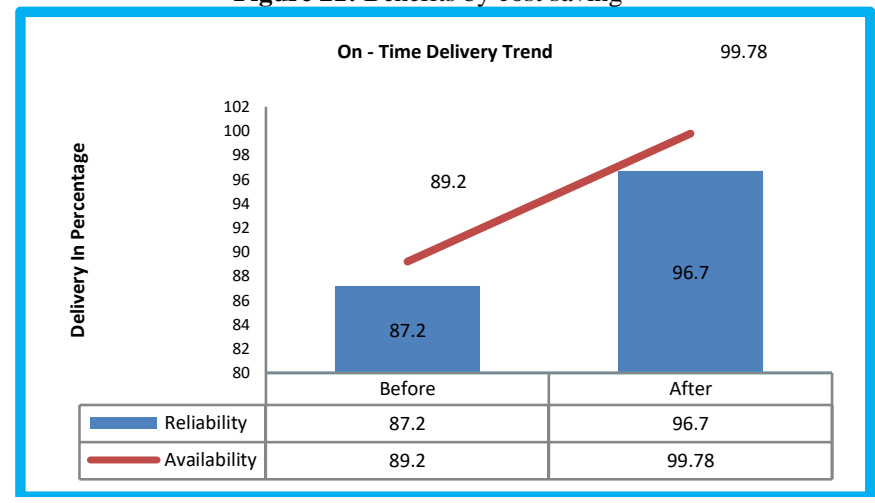

Figure 22: Benefits on delivery

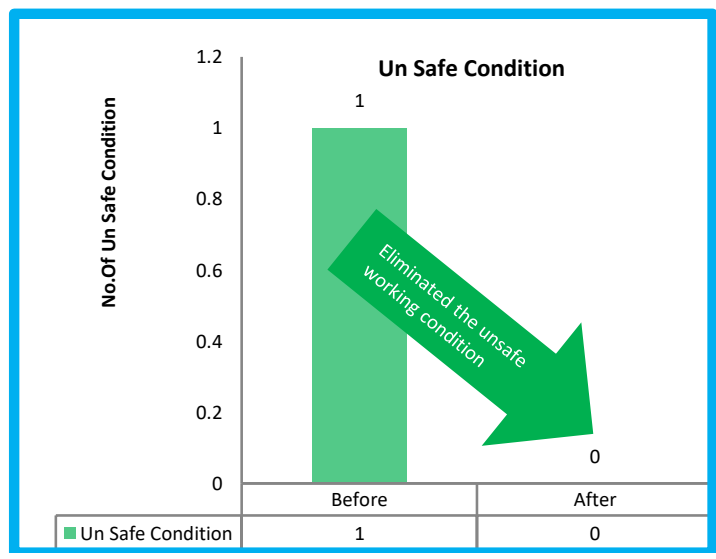

Figure 23: Benefits on safety

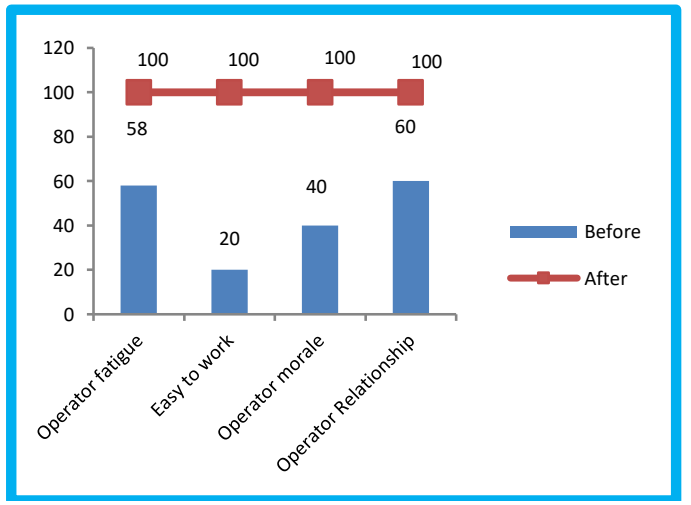

Figure 24: Benefits on motivation and morale

The productivity benefits measured in terms of number of pieces completed and total cycle time and achieved $36 \%$ improvement, the cycle time per piece is reduced from 9.17 seconds to 4.18 seconds, the motion losses and man power required are completely eliminated (refer Figure 19). According quality aspects, the rework completely eliminated, and rejection reduced to zero and cost saving Rs.8700/- achieved. The most important defect of missing of Punch was reduced to zero from 69. The rework PPM achieved zero from 48916 (refer Figure 20). The cost benefits measured in terms of rework elimination, rejection 
elimination, achieved zero motion loss and manufacturing point of view. The cost saving per annum Rs.4,72,503/- (refer Figure 21). The delivery achieved to highest value and presented in terms of reliability and availability in Figure 22. Due to automation of punching $100 \%$ safety ensured (Figure 23) and the operator motivation and morale were measured in terms of operator fatigue, work nature, morale and operator relationship and ensured $100 \%$ in all categories by implementing on line punching system. The benefits are consolidated in the Table 1 for easy reference.

Table 1: Benefits summary comparison for before and after

\begin{tabular}{|c|c|c|c|}
\hline \multirow[t]{2}{*}{ S.No } & \multirow[t]{2}{*}{ Description } & \multicolumn{2}{|c|}{ Benefits Summary } \\
\hline & & Before & After \\
\hline 1 & Assembly cycle time & $109 \mathrm{Sec}$ & $80 \mathrm{Sec}$ \\
\hline 2 & Production Qty & 264 No's & 360 No's \\
\hline 3 & Productivity & Less than $36 \%$ & $36 \%$ Improved \\
\hline 4 & Punching cycle time & $9.17 \mathrm{Sec}$ & $4.18 \mathrm{Sec}$ \\
\hline 5 & Operator motion losses & $7.08 \mathrm{Sec}$ & $0 \quad$ Sec \\
\hline 6 & Rework Qty & 587 No's & Sec \\
\hline 7 & Rejection Qty & 29 No's & $\mathrm{Sec}$ \\
\hline 8 & Punch Missing & 69 No's & $\begin{array}{ll}0 & \mathrm{Sec} \\
\end{array}$ \\
\hline 9 & Rework PPM & 79216.83 PPM & 48916.67 PPM \\
\hline 10 & Rejection Cost & Rs.8700/- & Rs.0/- \\
\hline 11 & Manpower consumption & 1 Manpower & 0 \\
\hline 12 & Rework Cost & Rs.87428.32/- & Rs.53762.5/- \\
\hline 13 & Motion Losses & Rs.19842.21/- & Rs.16793.28/- \\
\hline 14 & Manufacturing Cost & Rs.49686/- & RS.38870/- \\
\hline 15 & Availability & $89.20 \%$ & $99.78 \%$ \\
\hline 16 & Reliability & $87.20 \%$ & $96.70 \%$ \\
\hline 18 & Unsafe working condition & Yes & No \\
\hline 19 & Operator fatigue & $58 \%$ & $100 \%$ \\
\hline 20 & Easy to use & $20 \%$ & $100 \%$ \\
\hline 21 & Operator morale & $40 \%$ & $100 \%$ \\
\hline 22 & Operator relationship & $60 \%$ & $100 \%$ \\
\hline
\end{tabular}

\section{Conclusion}

Zero defect approach discussed with case study. The use of traditional powerful tools and modern measure of project outcomes (PQCDSM) also illustrated well. Lot of pictures included for easy understanding. The tangible results achieved and presented. This work made attempt on one product only and suggested to extend other products to continue the journey of success.

\section{References}

[1] Vafeiadisa T, Ioannidisa D, Ziaziosb C, Metaxab IN \& Tzovarasa $\mathrm{D}$, "Towards robust early stage data knowledge-based inference engine to support zero-defect strategies in manufacturing environment", Procedia Manufacturing, Vol.11, (2017), pp.679685.

[2] Boshkoska BM, Bohanec M, Boškoski P \& Juricic D, "Copulabased decision support system for quality ranking in the manufacturing of electronically commutated motors", Journal of Intelligent Manufacturing, Vol.26, No.2, (2015), pp.281-293.

[3] Ozgur UH \& Wendel G, "A fuzzy quality control-decision support system for improving operational reliability of liquid transfer operations in laboratory automation", Expert Systems with Applications, Vol.36, No.4, (2009), pp.8064-8070.

[4] Ribeiro A, "Fuzzy space monitoring and fault detection applications", Journal of Decision System, Vol.15, No.2-3, (2006), pp.267-286.

[5] Dunning T \& Friedman E, Practical machine learning: a new look at anomaly detection, O'Reilly Media, Inc., (2014).

[6] Zoesch A, Wiener T \& Kuhl M, "Zero Defect Manufacturing: Detection of Cracks and Thinning of Material during Deep Drawing Processes", Procedia CIRP, Vol.33, (2015), pp.179-184.

[7] Elbestawi MA \& Dumitrescu M, "Tool condition monitoring in machining-neural networks", Information Technology for Balanced Manufacturing Systems, (2006), pp.5-16.

[8] Saravanan R., Maniraj M \& Anin Vincely D, "Measurement is a mother of improvement-a Case Study", Proc. of the International Conference on Emerging Research and Advances in Mechanical Engineering, (2009).
[9] Saravanan R, Ponmurugarajan ST \& Sivakumar TK, "Chronic Loss Elimination by using TPM strategy in Manufacturing- a Case Study", 12th ISME National Level Conference on " Challenges In Product And Process Design And Development In The Information Era, (2001). 